\author{
Journal \\ Peqguruang: Conference Series \\ eISSN: 2686-3472
}

JPCS

Vol. 3 No. 2 Nop. 2021

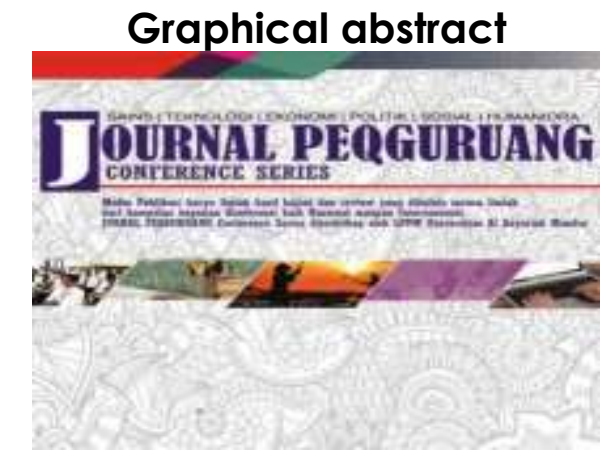

\title{
SISTEM DONASI PENYANDANG MASALAH KESEJAHTERAAN SOSIAL (PMKS) BERBASIS WEBSITE
}

\author{
1*Sinar Wahyu, 2Syarli, 3Idhan Zaldy, \\ 1,2,3Universitas Al Asyariah Mandar. \\ *Corresponding author \\ ayupolman99@gmail.com
}

\begin{abstract}
People with Social Welfare Problems (PMKS) are groups or individuals who are unable to carry out their social functions properly. The current problem is that the distribution of aid is still not right on target and data processing takes a lot of time. This study aims to create a system that can facilitate the distribution of assistance to the community, especially to people belonging to the category of People with Social Welfare Problems. In the process of collecting data, the researcher implemented qualitative methods by collecting data starting from observations, questionnaires, interviews and literature studies which would be processed into a single unit to be used as decision making material. The results of this study are a Donation System for Persons with Social Welfare Problems which is expected to provide a new innovation regarding Persons with Social Welfare Problems that can be implemented into a program at several Dinas offices in Polewali Mandar district, the program is made according to the design has been designed so that it can meet the users of an integrated system with related agencies that is used as a medium for distributing aid without having to go to the location where the PMKS is located. This application program is made using the PHP programming language, MySQL as the database and Codeighniter as the Framework.
\end{abstract}

Keywords: Administration, Assistance, PMKS, integrated.

\section{Abstrak}

Penyandang Masalah Kesejahteraan Sosial (PMKS) adalah sekelompok maupun individu yang tidak mampu melaksanakan fungsi sosialnya dengan baik. Permasalahan saat ini yakni penyaluran bantuan masih tidak tepat sasaran dan pengolahan data yang membutuhkan banyak waktu. Penelitian ini bertujuan untuk membuat sebuah system yang dapat mempermudah penyaluran bantuan kepada masyarakat terkhusus kepada masyarakat yang tergolong kedalam kategori Penyandang Masalah Kesejahteraan Sosial. Dalam proses pengumpulan data yang dilakukan, peneliti mengimplementasikan metode kualitatif dengan cara pengumpulan data mulai dari observasi, kusioner, wawancara dan studi pustaka yang akan diolah menjadi satu kesatuan untuk menjadi bahan pengambilan keputusan. Hasil dari penelitian ini yakni sebuah Sistem Donasi Penyandang Masalah Kesejahteraan Sosial yang diharapkan dapat memberikan sebuah inovasi yang baru mengenai Penyandang Masalah Kesejahteraan Sosial yang dapat di implementasikan menjadi sebuah program pada beberapa kantor Dinas yang ada di kabupaten Polewali Mandar, program yang dibuat sesuai dengan desain yang telah dirancang dengan tujuan dapat memenuhi pemakai sistem yang terintegrasi dengan instansi terkait yang digunakan sebagai media penyaluran bantuan tanpa harus mendatangi lokasi PMKS berada. Program aplikasi ini dibuat dengan menggunakan bahasa Pemrograman PHP, MYSQL sebagai database dan Codeighniter sebagai Framework.

Kata kunci: Administrasi, Bantuan, PMKS, terintegrasi. 


\section{PENDAHULUAN}

Kemajuan teknologi data di era 4.0 saat ini membuat sebagian besar kantor pemerintah melakukan berbagai perbaikan dalam hal administrasi dan pelayanan kepada masyarakat yang sesuai dengan perkembangan zaman (Oktaviana, 2020). Pentingnya inovasi data dalam pengorganisasian sumberdaya saat ini semakin dirasakan, terutama dengan peningkatan informasi, maka proses data tersebut secara manual akan terasa sangat sulit (Harpyani pugoy rannu, 2019). Penggunaan Sistem Informasi sangat penting untuk membantu kegiatan kerja. Dengan peningkatan teknologi yang telah merambah kesemua bidang untuk mengatasi masalah kebutuhan informasi dan manajemen data yang efektif (Syarli, 2019). Dengan perkembangan teknologi saat ini, maka setiap pengambilan keputusan dapat diambil oleh perencana, berdasarkan beberapa pertimbangan yang dianggap relevan sehingga tercapai sinergitas antar organisasi atau setiap tingkatan manajemen (Qashlim, 2019). Teknologi Informasi dapat digolongkan menjadi kebutuhan primer masyarakat saat ini karena manfaatnya yang sangat luar biasa (Zaldi, 2019).

$$
\text { Adanya suatu sistem }
$$
terkomputerisasi dalam berbagai informasi kependudukan akan membuatnya lebih mudah untuk merekam dan menangani informasi, mengurangi kesalahan dalam pencatatan dan penanganan serta menghasilkan laporan berdasarkan klasifikasi khusus sesuai yang dibutuhkan (Taufik, 2008). Hal ini berakibat semakin dibutukannya komputerisasi data yang dapat membantu menyelesaikan tugas-tugas yang berkaitan dengan masalah administrasi sehingga penyajian informasi menjadi cepat dan tepat (Permanasari, 2010). Adanya media informasi pendukung yang mampu memecahkan masalah sangat diperlukan sehingga informasi yang dihasilkan sesuai dengan kebutuhan. (Purnama, 2012).

Pengembangan sistem informasi pendataan dimaksudkan untuk memudahkan proses pengumpulan data warga yang terintegrasi sistem dan memudahkan untuk melihat informsi penduduk yang akan mendapatkan bantuan. (Saputro, 2020) Penyajian data dan pembuatan kumpulan data tentang Penyandang Masalah Kesejahteraan Sosial yang selanjutnya diharapkan dapat memperkecil kesalahan yang mungkin terjadi dan dapat memberikan laporan secara cepat dan tepat. (Suleman et al., 2019) Ketersediaan data Merupakan kebutuhan utama dalam merumuskan suatu keputusan maupun program. (Nurhaeni, 2020).

Berdasarkan uraian di atas maka penulis akan melakukan sebuah penelitian yang diharapkan nantinya dapat mempermudah proses kerja instansi terkait untuk mendapatkan informasi yang jelas dan akurat terkhusus pada Penyandang Masalah Kesejahteraan Sosial. Penelitian ini dibuat dalam bentuk sistem informasi dengan judul "Sistem Donasi Penyandang Masalah Kesejahteraan Sosial (PMKS) berbasis Website".

Tujuan dari penelitian ini yaitu untuk membuat suatu sistem donasi yang dapat mempermudah penyaluran bantuan kepada masyarakat yang tergolong PMKS. 


\section{METODE PENELITIAN}

\section{A. Waktu dan Tempat Penelitian}

Dalam proses pengumpulan data, peneliti melakukan penelitian di 4 (Empat) lokasi yakni, Kantor Dinas Pendidikan dan Kebudayaan, Kantor Dinas Sosial, Kantor Dinas Kesehatan dan Kelurahan Sulewatang yang ada di kabupaten Polewali Mandar, yang dilaksanakan selama 3 (Tiga) bulan terhitung bulan Februari sampai dengan April tahun 2021.

\section{B. Tahapan Penelitian}

Agar proses pengumpulan data berjalan dengan baik dan sistematis maka tahapan penelitian dipandang perlu ditetapkan sebagai pedoman dalam penelitian ini. Tahapan penelitian berisi data tentang apa yang akan dibuat selama proses pelaksanaan penelitian, Adapun tahapan yang akan dilaksanakan akan diuraikan pada gambar berikut

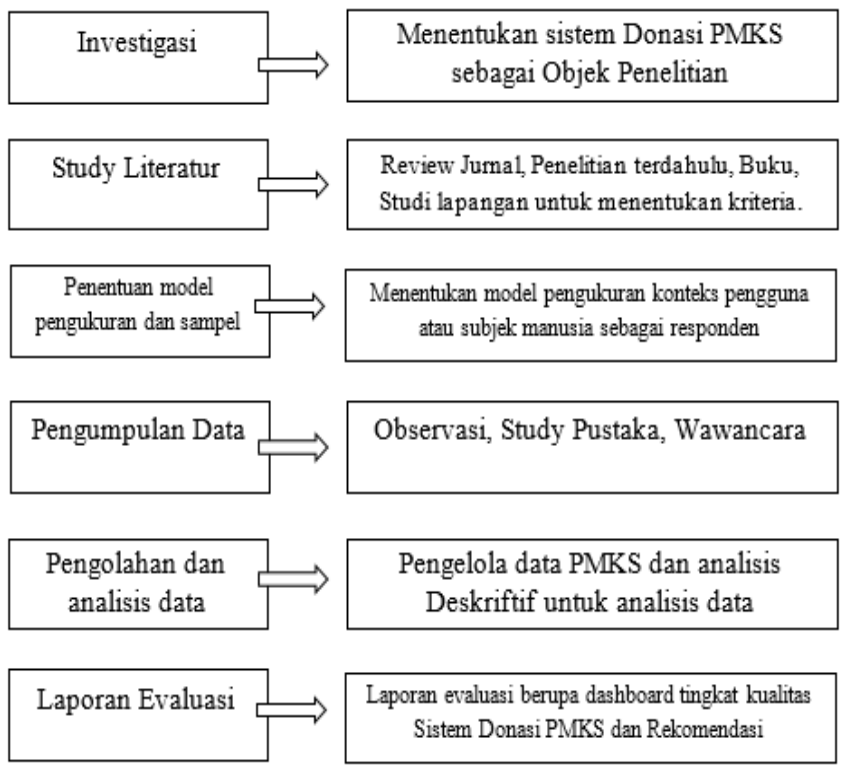

Gambar 1.1. Tahapan Penelitian

\section{Teknik Pengumpulan Data}

\section{Observasi}

Dalam penelitian ini peneliti melakukan observasi pada empat lokasi penelitian khususnya mekanisme penyaluran bantuan PMKS.

\section{Studi Pustaka}

Pada tahap ini peneliti mengumpulkan informasi dengan mengkaji beberapa referensi yang relevan dengan pokok permasalahan yang sedang diteliti, seperti dari buku dan jurnal.

\section{Wawancara}

Pada tahap ini penelitian melakukan wawancara dengan pihak instansi yang terkait yakni Dinas Pendididkan dan Kebudayaan, Dinas Sosial, Dinas Kesehatan dan Kelurahan.

\section{Teknik Analisis Data}

Setelah informasi dikumpulkan melalui wawancara, observasi atau melalui sumber opsional lainnya maka selanjutnnya data akan di edit. Data dikodekan dan pengelompokan data harus diurutkan menurut variable. Data tersebut akan di masukkan kedalam program perangkat lunak untuk dianalisis.

\section{E. Kerangka Pikir}

Berikut akan digambarkan proses pengerjaan sistem yang akan di kembangkan, untuk itu penulis akan memaparkan dalam bentuk gambar sebagai berikut: 


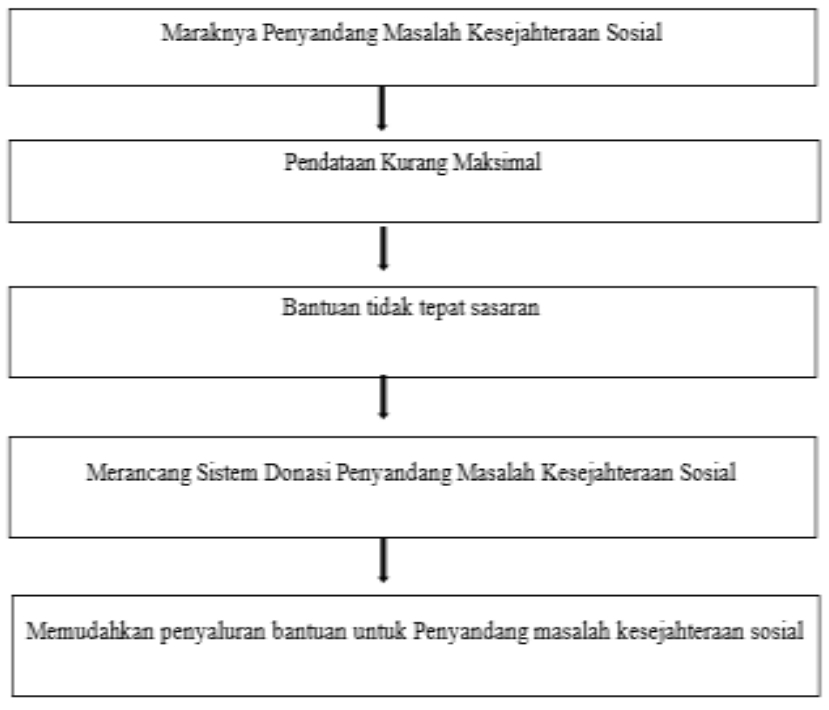

Gambar 1.2. Kerangka Pikir

\section{F. Kerangka Sistem}

Kerangka terdiri dari input, proses dan output dalam aplikasi yang akan dibuat pada gambar 1.3 berikut ini:

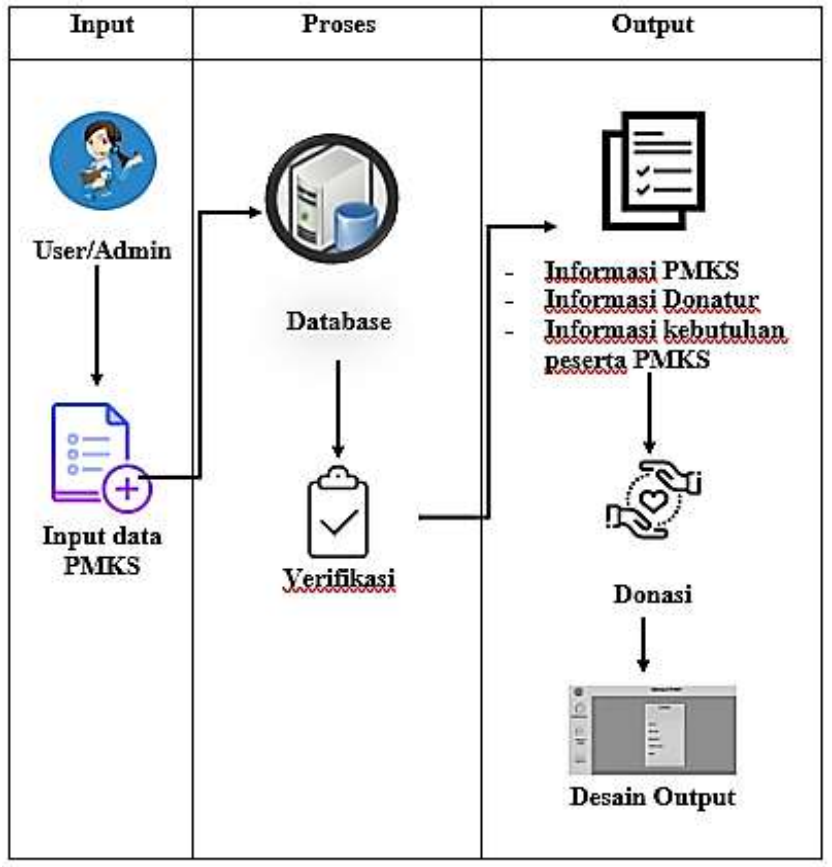

Gambar 1.3. Kerangka Sistem

Berdasarkan kerangka sistem yang telah dirancang, Admin PKMS Kelurahan melakukan proses input data. Kemudian data yang telah di input akan diproses didalam database yang akan diverifikasi sebelumnya, yang outputnya berupa informasi calon penerima bantuan. Setelah itu, donatur akan dapat memilih PMKS yang akan disalurkan donasi.

\section{HASIL DAN PEMBAHASAN}

\section{A. Hasil}

Berdasarkan hasil penelitian dan desain yang telah dibuat, kemudian pada tahap ini akan diterapkan hasil desain tersebut menjadi sebuah program pada beberapa Kantor Dinas yang ada di kabupaten Polewali Mandar yang dibuat dengan memakai Bahasa pemrograman PHP dan Xamp, program yang dibuat mesti selaras dengan desain yang sudah dirancang sehingga mampu memenuhi pengguna sistem. Pada bagian ini racangan sistem diartikan kedalam kode-kode dengan memakai Bahasa pemrograman yang telah ditentukan.

\section{Analisis Kelayakan Sistem}

- Kelayakan Teknologi

Secara teknologi sistem Donasi Penyandang Masalah Kesejahteraan sosial berbasis website ini layak digunakan untuk mempermudah pengguna dalam melakukan penginputan data PMKS agar secapatnya mendapatkan bantuan.

\section{- Kelayakan Operasioanal}

Elemen-elemen yang terdapat dalam aplikasi ini bisa dengan mudah dipahami oleh pengguna karena menggunakan Bahasa yang sederhana. Sehingga aplikasi ini layak untuk dioperasionalkan.

\section{User Interface Program}

Berikut merupakan tampilan program pada sistem yang telah dibuat.

\section{a. Form Menu Utama}


Menu Utama adalah tampilan yang akan dijumpai pertama kali ketika pemakai system melakukan akses ke aplikasi. Menu Utama berisi beberapa fitur diantaranya Beranda, Registrasi Donatur, Login Donatur, lihat data Donatur, Data PMKS dan Login Admin.

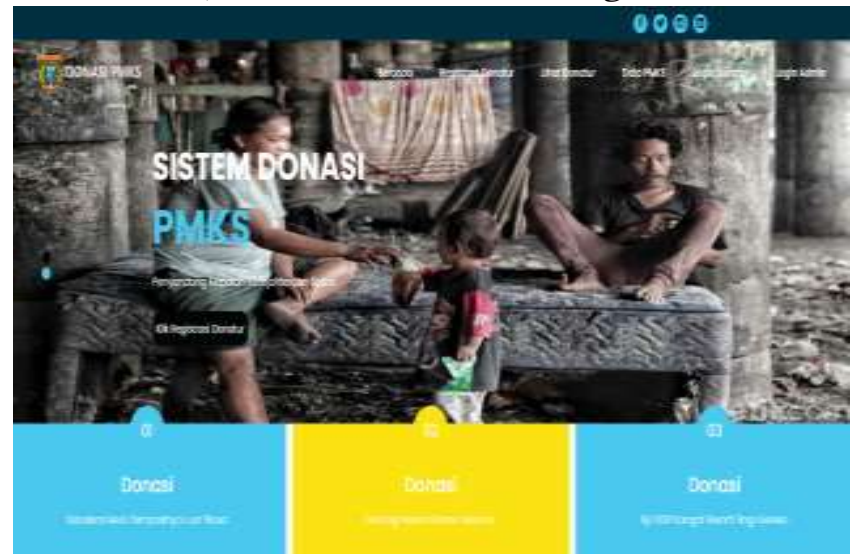

Gambar 3.1. Tampilan Menu Utama

\section{b. Form Login}

Form login merupakan form yang dipakai admin untuk dapat melakukan pengolahan data.

\section{Silahkan Masuk}

\section{Username}

Password

\section{Masuk}

Kelurahan untuk menginput Data Warga yang membutuhkan uluran tangan.

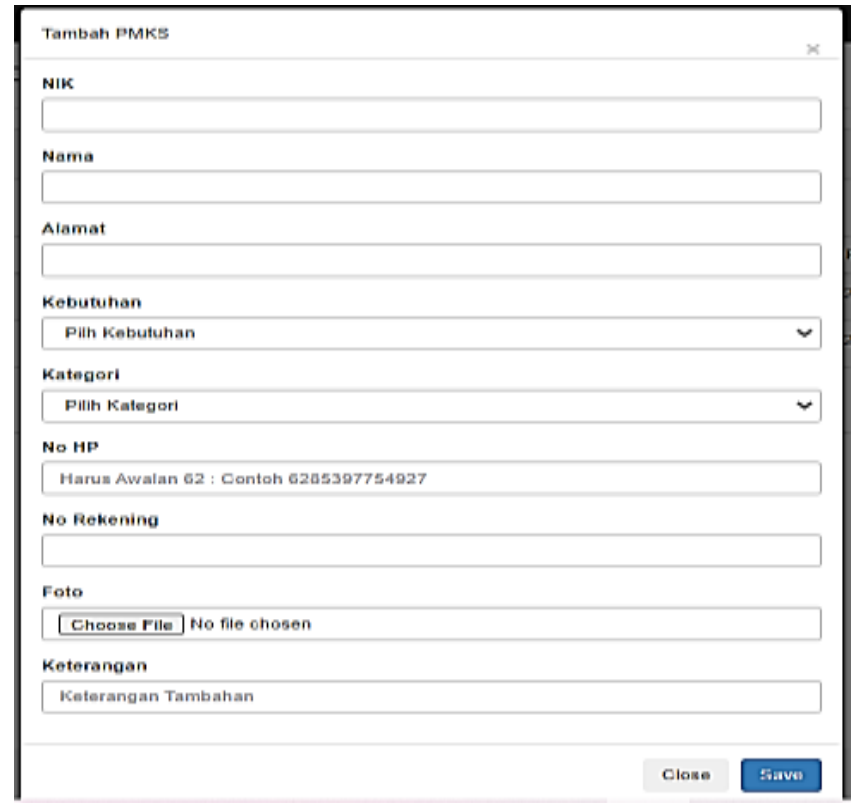

Gambar 3.3. Tampilan Tambah Data

d. Form Halaman calon penerima Halaman Calon penerima merupakan tampilan yang dapat dilihat dan dipilih oleh donatur sebelum melakukan donasi.

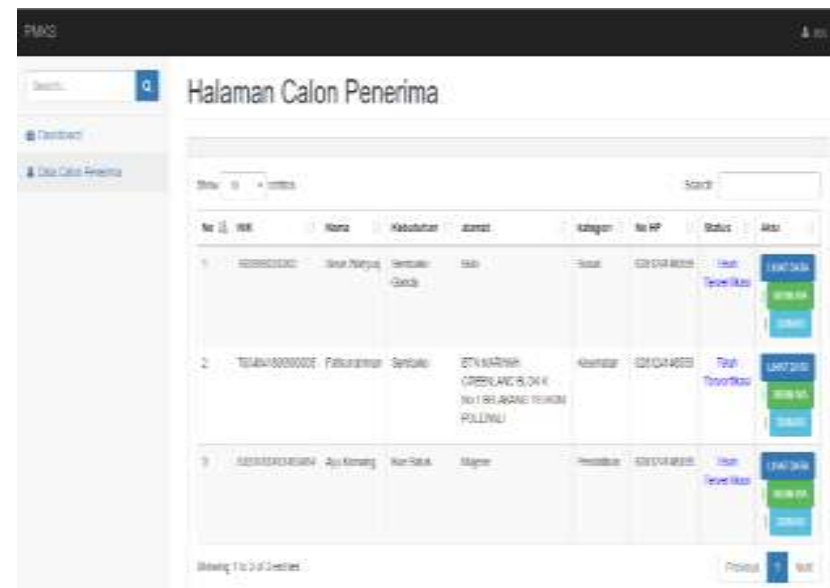

Gambar 3.4. Tampilan Halaman Calon Penerima

\section{e. Form Lihat Data PMKS}

Lihat data PMKS merupakan tampilan rinci data PMKS yang telah di input. 


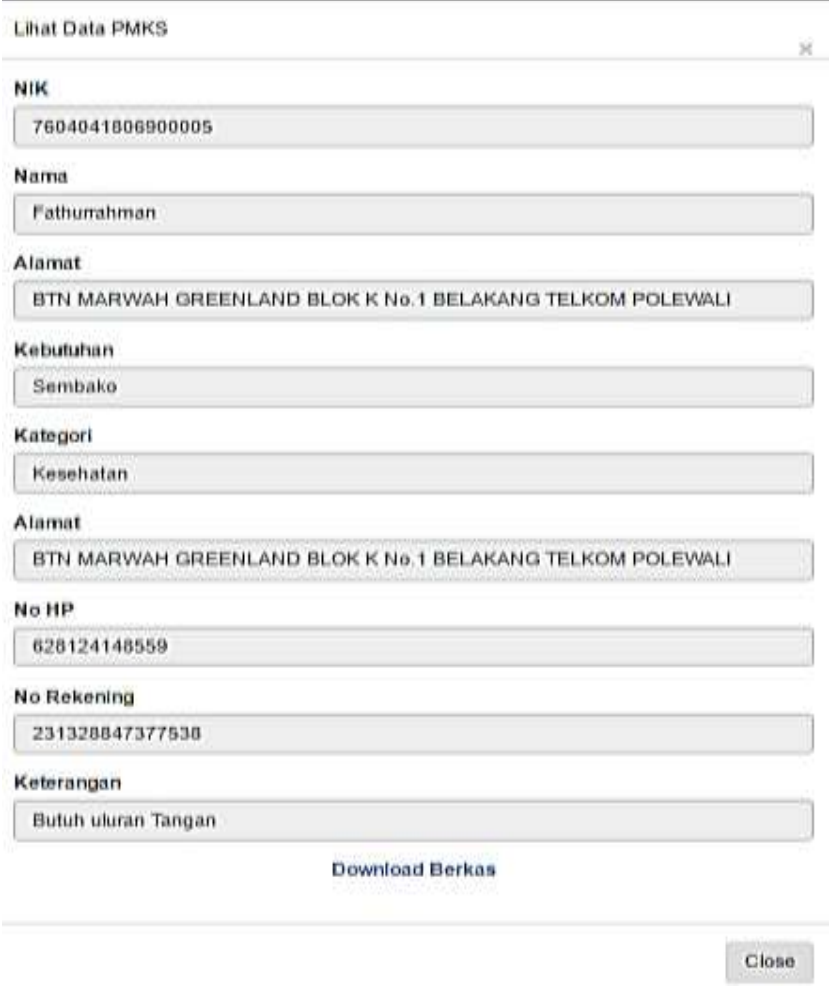

Gambar 3.5. Tampilan lihat data PMKS

\section{f. Form Registrasi Donatur}

Para Donatur harus melakukan registrasi dengan mengisi Form Nama Doantur, Email Donatur, Password, Nomor Handphone dan alamat untuk mendapatkan akses ke dalam aplikasi.

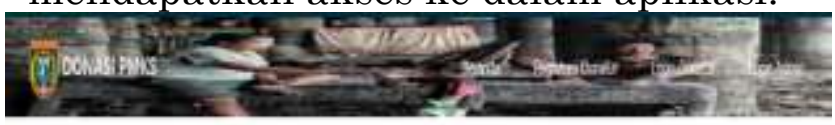

HALAUANREGITRAS DONHTUR para donatur untuk masuk kedalam aplikasi yang sebelumnya telah melakukan Registrasi.

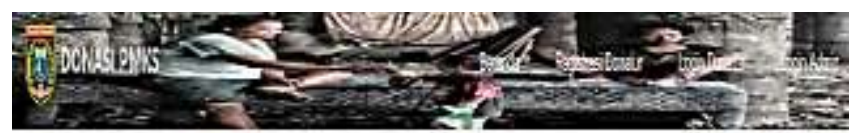

HALAMSIOOSDONGTR

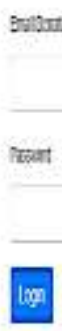

Gambar 3.7. Tampilan Login Donatur

h. Form Whatsapp PMKS

Form Whatsapp PMKS dapat di gunakan oleh para donatur untuk melakukan komunikasi langsung dengan calon penerima donasi.

KIRIM WA

NoHP

628124148559

Pesan

semoga sehat selalu|

Gambar 3.8. Tampilan Whatsapp PMKS 


\section{i. Form Donasi}

Form Donasi menampilkan nomor rekening calon penerima donasi.

\section{Benkut}

0139139210392013921

\begin{tabular}{|c|c|c|c|c|}
\hline & $\begin{array}{l}\mathrm{n} \\
\text { Donasi }\end{array}$ & & & \\
\hline 4. & $\begin{array}{l}\text { Halama } \\
\mathrm{n} \\
\text { Registr } \\
\text { asi }\end{array}$ & 1 & 1 & 1 \\
\hline 5. & $\begin{array}{l}\text { Login } \\
\text { Donatu } \\
\mathrm{r}\end{array}$ & 1 & 1 & 1 \\
\hline 6. & $\begin{array}{l}\text { Login } \\
\text { Admin }\end{array}$ & 1 & 1 & 1 \\
\hline 7. & $\begin{array}{l}\text { Lihat } \\
\text { Data } \\
\text { PMKS }\end{array}$ & 3 & 3 & 3 \\
\hline \multicolumn{2}{|c|}{ Jumlah } & 19 & 19 & 19 \\
\hline
\end{tabular}

Berdasarkan tabel di atas dapat di simpulkan bahwa aplikasi yang telah dibuat dianggap valid dan dapat dinyatakan terbebas dari kesalahan.

\section{SIMPULAN}

Berdasarkan hasil penelitian yang sudah dilaksanakan sejak awal sampai pelaksanaan pengujian terhadap aplikasi Sistem Donasi Penyandang Masalah Kesejahteraan Sosial (PMKS) berbasis website maka diberikan kesimpulan yaitu dengan adanya Sistem diharapkan memberikan kemudahan bagi pengguna untuk secepatnya mendapatkan dan berbagi informasi mengenai masalah yang dihadapi oleh warga yang termasuk dalam Penyandang Masalah Kesejahteraan Sosial itu sendiri sehingga dapat segera mengambil Tindakan.

$\begin{array}{lcccc}\text { N } & \text { Flowgra } & \text { Indepen } & \text { Regi } & \text { itas } \\ \text { o. } & \text { ph } & \text { det Path } & \text { on } & \text { Siklomati }\end{array}$

\begin{tabular}{llccc}
\hline 1 & $\begin{array}{l}\text { Menu } \\
\text { Utama }\end{array}$ & 7 & 7 & 7 \\
\hline 2. & $\begin{array}{l}\text { Tamba } \\
\text { h Data }\end{array}$ & 3 & 3 & 3 \\
\hline 3. & Halama & 3 & 3 & 3 \\
\hline
\end{tabular}


DAFTAR PUSTAKA

Harpyani pugoy rannu, D. (2019). Paulus Informatics Journal. 1(1), 21-26.

Kiki Fitri Auliah, Syarli, M. A. (2019). Peqguruang: Conference Series. 1(September), 1-8.

Nurhaeni, N. (2020). Klasifikasi Jenis Penyandang Masalah Kesejahteraan Sosial Menggunakan $\mathrm{NaA} \tilde{A}^{-}$ve Bayes. Jurnal Sains Dan Informatika, 6(1), 54-61.

https://doi.org/10.34128/jsi.v6i1.205

Oktaviana, M., Karnila, S., Informasi, P. S., \& Informasi, P. S. (2020). WebBased Information Systems for Services in the. 11, 54-59.

Permanasari. (2010). No Title

$\square \square .283$.

Purnama, B. E. (2012). Analisa Dan Perancangan Sistem Komputerisasi Pembelajaran Dengan Media Video Menggunakan Software Adobe Preemiere Di SMK Wisudha Karya Kudus. Journal Speed, 4(1), 28-35.

Qashlim, A. (2019). Peqguruang: Conference Series. 1(September), 1-8.

Saputro, D. (2020). PENGEMBANGAN SISTEM INFORMASI PENDATAAN BEDAH RUMAH BERBASIS WEB PADA DINAS PERUMAHAN RAKYAT DAN Abstrak. 2(1), 78-87.

Suleman, S., Pakaya, R., \& Daud, Y. (2019). Pendataan Penyandang Masalah Kesejahteraan Sosial (Pmks) Berbasis Web. Jurnal Teknologi Informasi Indonesia (JTII), 4(1), 3039.

https://doi.org/10.30869/jtii.v4i1.374

Taufik, M., Handayani, S., \& Prastyo, S. D. (2008). Sistem Informasi Pendataan Penduduk Pada Kantor Kepala Desa Ujungrusi Kabupaten Tegal. Media Elektrika, 1(2), 20-30.

Zaldi, I., H, Z. B., \& Baharuddin, M. (2019). SISTEM MANAJEMEN
PERPUSTAKAAN DIGITAL DENGAN TEKNOLOGI RFID PADA STT BARAMULI. 5(2), 27-31. 